AUTHOR CORRECTION OPEN

\title{
Author Correction: Vital role of magnetocrystalline anisotropy in cubic chiral skyrmion hosts
}

M. Preißinger (D), K. Karube, D. Ehlers, B. Szigeti, H.-A. Krug von Nidda, J. S. White (iD, V. Ukleev, H. M. Rønnow (D), Y. Tokunaga, A. Kikkawa, Y. Tokura (iD), Y. Taguchi (iD) and I. Kézsmárki

npj Quantum Materials (2021)6:70; https://doi.org/10.1038/s41535-021-00369-8

Correction to: npj Quantum Materials https://doi.org/10.1038/ s41535-021-00365-y, published online 07 July 2021

The original version of this Article omitted the following from the Acknowledgements:

"This work was partly supported by JST CREST(grant No. JPMJCR1874 and JPMJCR20T1)."

This has now been corrected in both the PDF and HTML versions of the Article.

\begin{abstract}
Access This article is licensed under a Creative Commons Attribution 4.0 International License, which permits use, sharing, adaptation, distribution and reproduction in any medium or format, as long as you give appropriate credit to the original author(s) and the source, provide a link to the Creative Commons license, and indicate if changes were made. The images or other third party material in this article are included in the article's Creative Commons license, unless indicated otherwise in a credit line to the material. If material is not included in the article's Creative Commons license and your intended use is not permitted by statutory regulation or exceeds the permitted use, you will need to obtain permission directly from the copyright holder. To view a copy of this license, visit http://creativecommons.org/licenses/by/4.0/.
\end{abstract}

(c) The Author(s) 2021 